\title{
Erratum to: Analysis of pumping test data for determining unconfined-aquifer parameters: Composite analysis or not?
}

\author{
Hund-Der Yeh • Yen-Chen Huang
}

Erratum to: Hydrogeology Journal (2009), 17:1133-1147

DOI 10.1007/s10040-008-0413-z

The horizontal axis labels for Fig. 4 of this article were incorrect. The correct version is presented here.

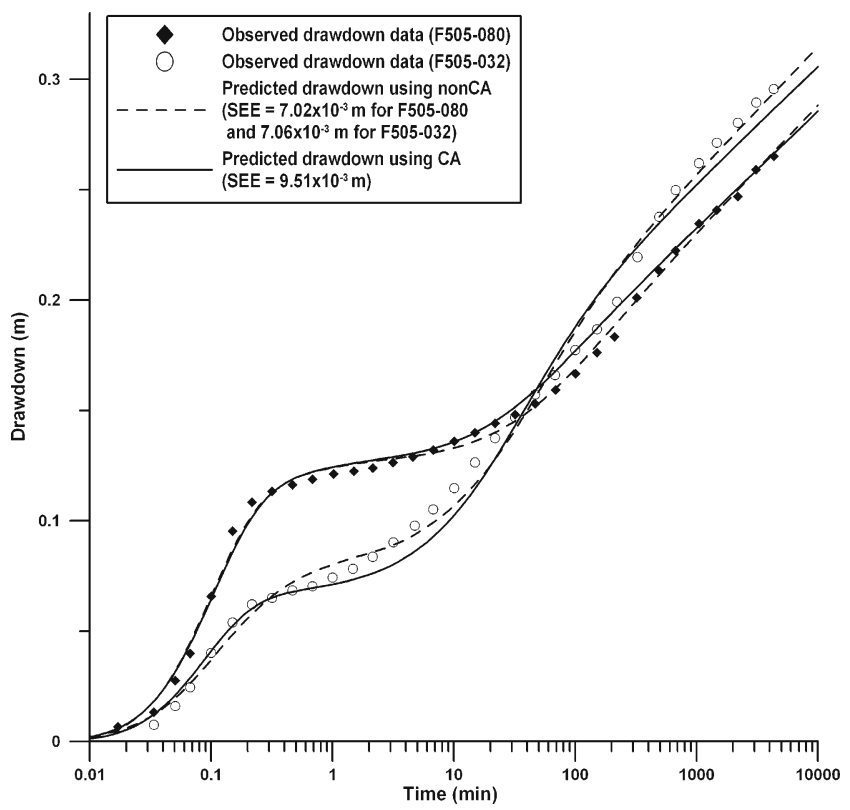

Fig. 4 The drawdown curves predicted by Neuman's solution (Neuman 1974) with parameters determined from nonCA and CA for wells F505-032 and F505-080

Published online: 9 October 2010

(C) Springer-Verlag 2010

The online version of the original article can be found at http://dx.doi.org/10.1007/s10040-008-0413-z.

H.-D. Yeh $(\varpi) \cdot$ Y.-C. Huang

Institute of Environmental Engineering,

National Chiao Tung University,

1001 University Road, Hsinchu, 300, Taiwan

e-mail: hdyeh@mail.nctu.edu.tw

Tel.: +886-3-5731910

Fax: +886-3-5726050

Y. Huang

e-mail: ychuang1225@gmail.com 